\title{
Performance of combined tillage equipment and it's effect on soil properties
}

\author{
Ayad J. ALkhafaji ${ }^{1}$, Abdulaziz A. Almosawi ${ }^{2}$, Kamal M. Alqazzaz ${ }^{1}$ \\ ${ }^{1}$ Agricultural Mechanization Faculty of Agriculture, University in Kufa, Iraq \\ iyad.alkhafaji@uokufa.edu.iq \\ ${ }^{2}$ Alforat Alawsat Tech. University, Diwania Technical Institute, Iraq
}

\begin{abstract}
An experiment was conducted to evaluate the performance of a locally manufactured combined tillage implement (moldboard plow + ripper) in one of the fields of the kufa university faculty of agriculture. The experiment was included two factors, the first factor is combing the ripper to mold board plow in five level these are fixing the combined ripper shanks while the shanks points oriented in two different levels with and opposite to the plowing direction, two levels of different ripper depths the same depth and $5 \mathrm{~cm}$ above the depth of mold board plow share and the fifth level is control treatment ( mold board plow alone). The second factor was the plowing operation speed at five levels (1.4, 2.0, 3.6 and 4.7) Km.hr - 1 . the experiment was conducted as a factorial experiment with RCBD, the LSD test at $5 \%$ was used to compare between means. The results of the research were showed that combining the locally manufactured ripper implement to mold board plow resulted in significant increase in the number of soil clods with the desired diameter $(5-10 \mathrm{~cm})$ very low number of soil block with diameter larger than $10 \mathrm{~cm}$, more even soil roughness and the actual productivity has not decreased to the extent that it affects the efficient performance of the tillage process compared to the use at the mold board plow alone.
\end{abstract}

Keywords—combination, tillage, soil, roughness, ripper , moldboard.

\section{INTRODUCTION}

Now a days, the conventional tillage practices are very expensive in cost, more time consuming and higher number of passes which cause soil compaction. Furthermore; conventional tillage is considered to be one of the low fuel-efficient operation. Digman 2012 mentioned that only $20 \%$ of diesel fuel energy is available at the tractors drawbar, however, only $4 \%$ out of that energy is converted in to breaking up the soil . Therefore, it is so important to find out an early way leading to get the most out of tillage operation, one way to bypass these problems is the use of combined tillage implements in one field operation. This practice is useful only for those who prefer the use of conventional tillage practices such as the
Iraqi farmers. Manjeet et al. 2016 defined the combined tillage is the way in which two or more implements operates at the same time in order to manipulate the soil. In general sense, combined tillage means integrated management of resources such as time, energy, fuel, labor, soil and water conservation, on the other hand, increasing yield and better utilize of natural resources. It also contributes and sustained agriculture production. Nasr et al 2016divided the combined agricultural implements intofive groups these are:1-Soil preparation.2-soil preparation andfertilizing. 3-soil preparation ,fertilizing and seeding. 4-soil preparation and seeding. 5-fertilizing and seeding. For each of thefive groups mentioned they suggested two or more operations e.g the third group mentioned above has three operations these are plowing, fertilizing and seeding; tilling, fertilizing and seeding and cultivating fertilizing and seeding. Grisso et al (2012) revealed that combined implements operations reduce fuel consumption, time and labor requirements by limiting at least one individual trip over the field. Javadi et al. 2006 , Asgill 2008 and Manjeet et al 2016 revealed that combination tillage implements were more energy efficient , higher tillage performance index (TPI) and saving nearly $50 \%$ in cost and $50 \_55 \%$ in timecompared with the same single passive tillage implement .

Moitzi et al. 2014 revealed that the area - specific fuel consumption increased linearly with working depth for moldboard plow and short disc harrow, but disproportionately for subsoil. Wheel slip was also found to increase fuel consumption and decrease field capacity performance at all depth. The concept of combination tillage practice was entered into force for the primary and secondary tillage operations since hundred year ago (Shafee 1995), but is still not widespread even in places where this application is needed, such as rice cultivation in southern Iraq. Theobjectives of this research were to investigate the performance of the developed combined implement in terms of it effect on :

1- Improving soil refined and surface uniformity .

2- Saving time and fuel consumption . 


\section{MATERIAL AND METHOD}

\section{Description of the developed implement:}

A combination implement was developed at the faculty of agriculture university of Kufa in order to meet the seedbed requirements by sufficient loosening field soil breaking clods and gaining a uniform soil bed in a single pass and least time. Fig 1 shows the developed implement which was combined from moldboard plow and locally manufactured heavy duty ripper. It had 6 shanks fixed into a heavy rectangular frame. The long sides of the rectangle form the two rows of the ripper and the shanks placed in equal and interlaced spaces .

However for optimum performance the spaces was set equal to $40 \mathrm{~cm}$ in the same row. The unique ripper is attached to the end of the moldboard plow chassis so that the extension of the pull line passes through the center of the ripper tool. The plow and the ripper work as one unit, when the moldboard plow raised hydraulically it picks up the ripper too .


Fig 1 Top: the shanks position behind the bottoms of the moldboard plow, bottom :the combined implements (moldboard plow + ripper $)$

During plowing the front shanks of the ripper hit with the center of the inverted slices that are usually formed by moldboard the result is dismantling and breaking the slices and displacing some of the clods and soil to the sides. Here comes the role of the rear row shanks in disassembling the rest of slices and handle the big clods that were displaced by the front shanks. Moreover the developed implement makes the ground more even . The ripper shanks were designed to be easily adjusted in depth , however the adjustment was set according to the moldboard plow depth. The ripper shanks points ( shovels) were made from heavy long wearing metal with dimensions of $15 \mathrm{~cm}$ length $2 \mathrm{~cm}$ thickness. Each point was supplied with two slotted holes so it can be fitted in the required center.

Test procedure :

An experiment was conducted at one of the agriculture field at the faculty of agriculture University of Kufa to test and evaluate the performance of the developed implement in term of breaking and pulverizing the field soil in one tractor pass .

The combined implement was pulled byMassy Fergusson tractor with nominate power $82 \mathrm{kw}$ and total mass 3250 $\mathrm{kgm}$. The test was performed according to $5 \times 5$ factorial split plots design with the randomized complete block design with three replicators . the experiment contain the following two factor:

1-Fixing thecombined ripper shanks while shanks points oriented in two different ways and two different depths taking in to consideration the depth of moldboard plow and control treatment (moldboard plow alone), these are :

a- Fixing the ripper shanks with shanks points orientedtoward the direction of tillage operation with two depths: same depth as plowing share (S1D1) and $5 \mathrm{~cm}$ above plowing depth(S1D2) fig 2

b- Fixing the ripper shanks with shanks points oriented opposite the direction of the tillage operation with two depths : same depth as plowing share depth (S2D1) and $5 \mathrm{~cm}$ above plowing depth (S2D2) fig 2 .

c- Control treatment, without the use of the ripper implement MB (moldboard plow alone) .

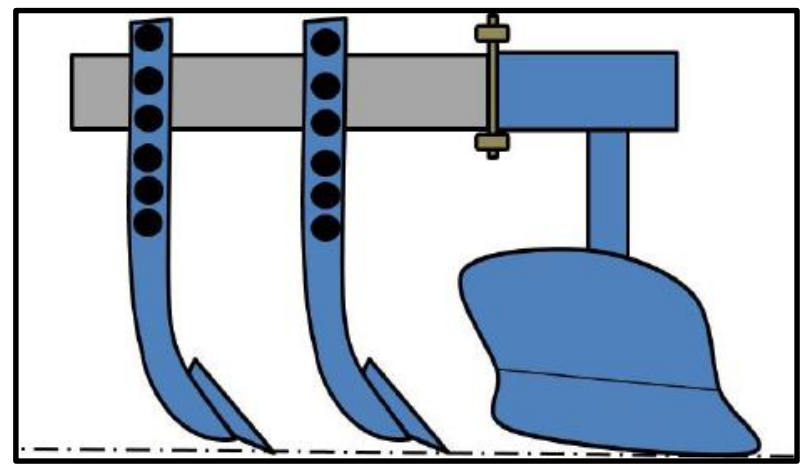




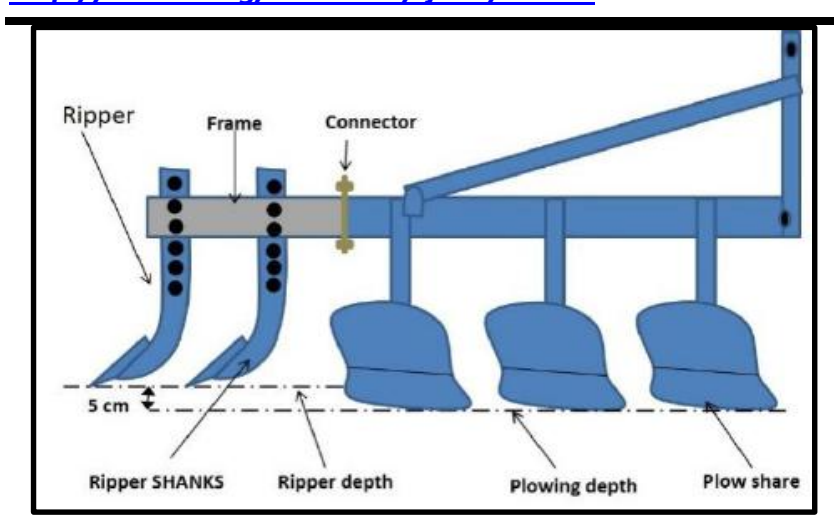

Fig 2 moldboard plow + ripper with two directions and two depths .

2- Tillage operation field speeds with five averaged levels



The quality of the tillage and operation performance were evaluated through the estimation of the following parameters :

1 - Soil refinement : it was determined by using two different size opining sieves. The substance of this test is to pass the soil of an area $50 * 50 \mathrm{~cm}$ picked randomly from the tillage treated soil through a $10 * 10 \mathrm{~cm}$ opining then through a $5 * 5 \mathrm{~cm}$ opining sieve .

2- Soil surface roughness index : it was determined by using the following formula :

$S D=\sqrt{\frac{\sum(d i-d)^{2}}{n}} \ldots \ldots . \mathrm{cm}$

Where :SD : soil roughness index , di : soil ripple height, which determined by use a wooden rectangle triangle with a $50 \mathrm{~cm}$ height and $2 \mathrm{~m}$ base length . before sampling the triangle was leveled and samples were taken every $10 \mathrm{~cm}$.

3 - Actual Productivity (ha. $\mathrm{hr}^{-1}$ ) :

A.P. $=0.1 * \mathrm{~W} * \mathrm{VP} * \mathrm{FE} \quad\left(\right.$ ha. $\left.\mathrm{hr}^{-1}\right) \ldots(2)$

Where : A.P.:W: active working width (m), VP: tillage operation speed $\left(\mathrm{km} . \mathrm{hr}^{-1}\right)$ and FE : field efficiency ( $60 \%)$.

3- Slippage $\%$ :

$\mathrm{S} \%=\frac{V T-V P}{V T} * 100 \%$

Where : S : slippage \%, VT: theoretical speed $(\mathrm{km}$. $\left.\mathrm{hr}^{-1}\right)$,

4- Fuel ConsumptionFu.C ( L .ha $\left.{ }^{-1}\right)$ :

Fu. $C=\left(Q^{*} * 10000\right) /\left(W^{*} \mathrm{D}\right)$

Where : Qd : treatment fuel consumption ( L) , D: treatment length $(\mathrm{m})$

\section{RESULTS AND DISCUSSION}

\section{Soil colds larger than $5 \mathrm{~cm}$ in diameter}

Table1shows that combining the manufactured ripper with moldboard plow to perform plowing operation has a significant effect on the size of soil clods larger than $5 \mathrm{~cm}$ in diameter compared to the use of moldboard plow alone (MP) and these are true results for all the combined implement treatments levels . These results are consistent with the published resultedby Manjeet et al (2016) . However the treatment of fixing the ripper shanks with the skanks points oriented opposite to the direction of plowing at the shallow depth (S2D2) exceeded the other treatments by achieving a number of 69.8 clods. $\mathrm{m}^{2}$ followed by the treatments with the greatest depth (S2D1) and the same implement shanks points orientation, while treatment of using moldboard plow alone recorded the least number of clods that was 32.1 clods . $\mathrm{m}^{2}$.

Table 1: Soil colds larger than $5 \mathrm{~cm}$ (clods. $\left.\mathrm{m}^{2}\right)$

\begin{tabular}{|c|c|c|c|c|c|c|}
\hline \multirow{2}{*}{ TRT } & \multicolumn{5}{|c|}{$\mathrm{V}\left(\mathrm{km} \cdot \mathrm{hr}-{ }^{1}\right)$} & \multirow{2}{*}{ Mean } \\
\hline & 1.4 & 2.0 & 3.6 & 4.2 & 4.7 & \\
\hline MB & 29 & 30 & 32.5 & 36 & 33 & 32.1 \\
\hline S1 D1 & 31.5 & 33.5 & 35.5 & 38.5 & 40.5 & 35.9 \\
\hline S1 D2 & 34.5 & 38.5 & 41 & 43.5 & 47.5 & 41.0 \\
\hline S2 D1 & 39.5 & 42.5 & 45 & 46 & 53.5 & 45.3 \\
\hline \multirow[t]{2}{*}{ S2D2 } & 64.5 & 66 & 70 & 75 & 73.5 & 69.8 \\
\hline & 39.8 & 42.1 & 44.8 & 47.8 & 49.6 & \\
\hline
\end{tabular}

Therefore the use of combining implement gave an excellent results in term of improving the size of soil clods with the suitable diameters .The results also revealed that the plowing speed has a significant effect on soil clod larger than $5 \mathrm{~cm}$ in diameter the number of soil clods increased as plowing speed increased. This is due the fact that increased the speed of plowing increased the impact speed of the plow bottoms and the ripper shanks against the soil slices formed by the plowshare, as a result increased the process of fragmentation of the soil blocks into smaller soil clods, similar results were found by Aboherbageet.al.(2010) when they tested a chisel plow at different speed .The interaction between operational speed and the combined implement at different shanks points orientation and different depths was significant so that the synthesis between the ripper combination and the high field speed at shallow depth and shanks points oriented opposite to plowing direction gave the highest number of soil clods.

\section{Soil clods larger than $10 \mathrm{~cm}$}

The results in table 2 and figure 3 indicate that the use of the combined implement (moldboard plow + ripper) has influenced the quality of the tillage operation, the clod size distribution was fairly appropriate where the high number of clods larger than $5 \mathrm{~cm}$ were found in table (2) and the low number of clods greater than $10 \mathrm{~cm}$ table 3 and the absence of clods greater than $20 \mathrm{~cm}$ in all combined implement treatment and has appeared in the moldboard plow treatment . Similar results were published by Servadio et. al (2016) . 
Based on the advanced findings we can conclude that combining the manufactured ripper behind the moldboard plow has worked to break the soil slices formed by the plow share and reduces the soil clods and increased their numbers compared to the treatment of moldboard plow alone .

Table.2: Soil colds larger than $10 \mathrm{~cm}\left(\mathrm{clods} . \mathrm{m}^{2}\right)$

\begin{tabular}{|c|c|c|c|c|c|c|}
\hline \multirow[t]{2}{*}{$T R T$} & \multicolumn{5}{|c|}{$V(k m \cdot h r-1)$} & \multirow[t]{2}{*}{ Mean } \\
\hline & 1.4 & 2.0 & 3.6 & 4.2 & 4.7 & \\
\hline$M B$ & 11.24 & 10.4 & 10.8 & 10.2 & 9.07 & 10.32 \\
\hline S1 D1 & 5.91 & 4.7 & 4.4 & 3.7 & 3.91 & 4.54 \\
\hline$S 1 D 2$ & 8.18 & 7.3 & 6.9 & 5.7 & 5.60 & 6.74 \\
\hline$S 2 D 1$ & 6.64 & 5.7 & 5.8 & 4.4 & 3.95 & 5.31 \\
\hline \multirow[t]{2}{*}{$S 2 D 2$} & 4.03 & 6.5 & 5.2 & 5.7 & 3.41 & 4.95 \\
\hline & 7.20 & 6.9 & 7.0 & 6.0 & 5.19 & \\
\hline \multicolumn{6}{|c|}{ LSD TRT $=0.064$ LSDTRT.V $=0.113$} & \\
\hline
\end{tabular}

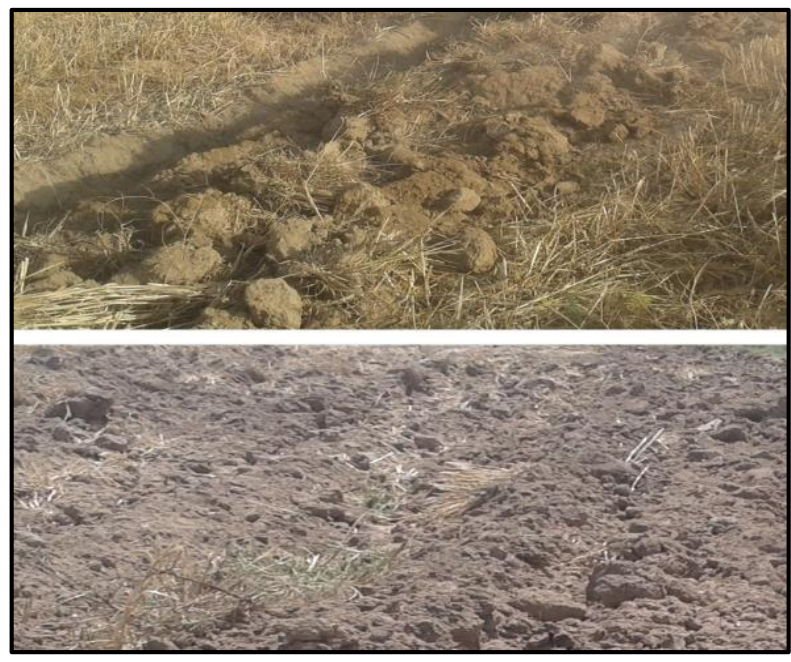

Fig.3: top :clods after the use of MP . bottom:clods after the use of combined implement.

Despite the emergence of a number of soil clods greater than $10 \mathrm{~cm}$ in the moldboard plow treatment (MB) table 3 but the apparent sign in this treatment is the surface of the plowing area large soil blocks and in most cases the soil slices remained intact and did not break into parts .It was also noticed the highest number of clods greater than 10 $\mathrm{cm}$ was at the treatment when the ripper shanks points oriented opposite to the direction of plowing (S2D2) with a number of clods equal to $13.5 \mathrm{clods} . \mathrm{m}^{2}$ and in diameter of 15 to $20 \mathrm{~cm}$ the reason for this result was the ripper shanks worked efficiently in breaking the large masses of soil inverted by the moldboard plow , then followed by the treatment with the largest depth and at same direction (S2D1) while the least number of soil clods recorded by the treatment when the ripper shanks point oriented with direction of plowing (S1D1) and its value was 4.5 clods . $\mathrm{m}^{2}$. The results in table 3 indicated that the speed had not significant in this parameter and it seems that the presence of large soil masses with large diameter counted on block increased the large disparity of the parameter between replicates with in the single treatments. As shown in table 3 and figure 2 . that the interaction between the combined implement and filed speed did not show a significant effect in this parameter due to the same reasons explained before .

\section{Soil surface roughness}

The results in table 3 and fig 4 illustrated that the treatment moldboard plow alone (MB) was the Highest variability of the soil surface roughens. This is very naturel result because of the stirring action of the plow and the dismantling soil to masses of different sizes which make the soil surface is more winding and uneven. However the use of the combined implement contributed to increased the leveling of soil surface . this was clear when the ripper shanks point oriented toward plowing direction in treatment (S1D2) which achieved the best degree of surface leveling compared to the rest of the treatments. That was happened due to the right shanks distribution behind soil layers formed by moldboard plow and the continues pushing of the soil in front of the shanks which have led to increased surface leveling . this treatment did not differ from the treatment when the ripper shanks point oriented opposite to the direction of plowing (S2D2) which achieved preference in surface roughens . this is due to the relatively high pulverizing efficiency of this treatment relative to the rest of treatments which contribute acquisition of a more even soil surface compared to the other treatment

Table 3: Soil surface roughens $(\mathrm{cm})$

\begin{tabular}{|c|c|c|c|c|c|c|}
\hline \multirow[t]{2}{*}{$T R T$} & \multicolumn{5}{|c|}{$V(k m \cdot h r-1)$} & \multirow[t]{2}{*}{ Mean } \\
\hline & 1.4 & 2.0 & 3.6 & 4.2 & 4.7 & \\
\hline$M B$ & 10 & 11 & 8.5 & 8 & 7.5 & 9 \\
\hline S1 Dl & 3.5 & 6.5 & 6 & 3.5 & 3 & 4.5 \\
\hline$S 1$ D2 & 8.5 & 7 & 6 & 9.5 & 6.5 & 7.5 \\
\hline$S 2 \mathrm{Dl}$ & 12 & 8 & 9.5 & 4.5 & 6 & 8 \\
\hline$S 2 D 2$ & 11 & 10.5 & 22 & 9 & 14.5 & 13.5 \\
\hline & 9 & 8.6 & 10.4 & 6.9 & 7.5 & \\
\hline
\end{tabular}




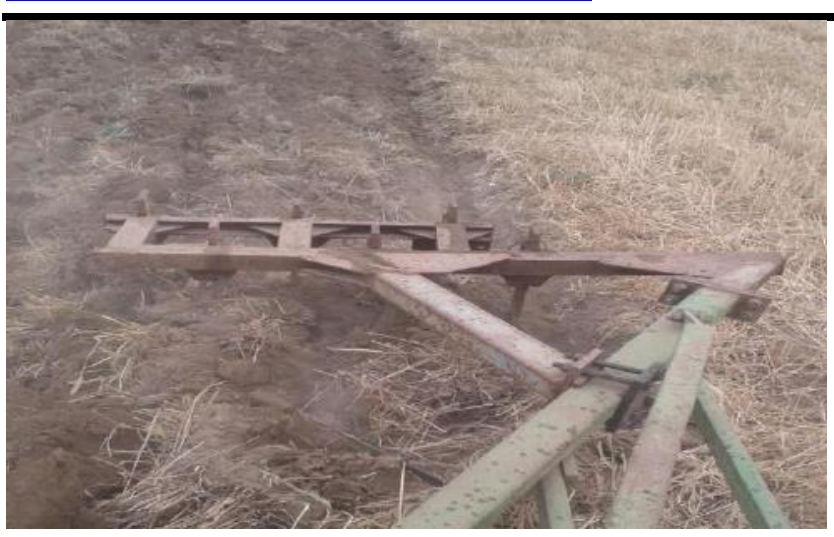

Fig.4 : soil surface before and after combined implement .

The results also showed that the highest speed caused the lowest surface roughness indicator this is may be due to the increased in velocity accompanied by an increase in the fragmentation of the soil matter into smaller fines. The binary interaction between the investigated factors showed that the treatment of the ripper shanks points projected opposite to the plowing direction (S1D1) with highest speed had the best level of surface roughest compared to the other treatment . Combining the ripper implement with moldboard plow during plowing process increased the tractor slippage percentage in all treatment tested. However this increased in slippage show variable differences relative to the shanks points orientation and the calibrated depth . Despite to this finding the result revealed that the combined implement when the ripper shanks point oriented opposite to the direction of plowing with the

\section{Tractor slippage}

shallow depth (S2D2) has achieved nearly close slippage percentage as compared with treatment of moldboard plow alone (MB) .The interpretation for these results were the ripper shanks had impacted directly soil slices which already cut and inverted by moldboard plow loosening them and lowering their resistance which made the shanks penetrate and sweep through easily.

However when the shanks depth increased to the depth of moldboard plow share (S2D1) the slippage of the tractor increased as a result of the excessive load. The results also showed that the use of the ripper with the shanks points oriented with the direction of plowing gave the highest tractor slippage specially when the shanks points fixed at the same depth as the moldboard plow share depth, the tractor slippage at this treatment reached at most $27 \%$ the big masses of soil and in front of the shanks obstruct the shanks movement which increased the load on the tractor lowering the tractor speed and hence the tractor slippage increased.
Table 5: Tractor Slippage \%

\begin{tabular}{|c|c|c|c|c|c|c|}
\hline \multirow[t]{2}{*}{$T R T$} & \multicolumn{5}{|c|}{$V(k m . h r-1)$} & \multirow[t]{2}{*}{ Mean } \\
\hline & 1.4 & 2.0 & 3.6 & 4.2 & 4.7 & \\
\hline$M B$ & 12.3 & 13.47 & 14.0 & 14.0 & 15.43 & 13.84 \\
\hline S1 D1 & 20.0 & 23.94 & 24.6 & 28.2 & 36.35 & 26.61 \\
\hline$S 1 D 2$ & 16.1 & 23.46 & 25.0 & 27.6 & 35.1 & 25.43 \\
\hline$S 2 D 1$ & 15.1 & 17.52 & 18.7 & 19.4 & 19.82 & 18.13 \\
\hline$S 2 D 2$ & 13.3 & 13.81 & 14.5 & 15.5 & 16.92 & 14.80 \\
\hline & 15.4 & 18.44 & 19.3 & 21.0 & 24.72 & \\
\hline \multicolumn{2}{|c|}{$L S D T R T=0.40$} & \multicolumn{4}{|c|}{$\begin{array}{l}\text { LSD TRT.V=0.38 LSDV } \\
\quad=0.21\end{array}$} & \\
\hline
\end{tabular}

The speed factor is the other factor which has a significant effect in the percentage of the slippage so as plowing speed increased the slippage percentage increased for all the treatment tested the reasons for this were the power required to break the soil increased and the impact speed that happened between the soil slices and ripper shanks was also increased which increased the actual time required to perform the work relative to the theoretical time which increased the tractor slippage. The slippage values in all combined implements treatment were out of the permitted limits except the treatment in which the shanks pointes oriented opposite to the tillage direction (S2D2) where the slippage within the permissible limits and this is true until the speed reached $4.2 \mathrm{~km} / \mathrm{hr}$. the interaction between the main factors was significant even though each factor has effected the slippage parameter independently which gave dam priority to (S2D2) treatment to get lowest slippage value $(13.27 \%)$ at the lowest speed.

\section{The actual productivity}

The actual productivity values and means of the studied factors have been tabulated in table 5. Despite the significant results of the actual productivity however a quick view of the results it can be concluded that the differences in productivity between the use of the moldboard plow (MB) alone or the combination with the ripper were not great enough to affect the efficient performance of the plowing process. The difference was 0.003 ha.hr $^{-1}$ between the use of the moldboard plow alone and the highest value achieved when the ripper combined with moldboard plow. It is considered very simple in comparison with applying another agriculture operation such as field cultivator or disc harrow to complete the seedbed preparation 
Table.6: Actual Productivity ( $\left.h a . h r^{-1}\right)$

\begin{tabular}{|c|c|c|c|c|c|c|}
\hline \multirow[t]{2}{*}{ TRT } & \multicolumn{5}{|c|}{$\mathrm{V}(\mathrm{km} \cdot \mathrm{hr}-1)$} & \multirow[t]{2}{*}{ Mean } \\
\hline & 1.4 & 2.0 & 3.6 & 4.2 & 4.7 & \\
\hline $\mathrm{MB}$ & 0.10 & 0.16 & 0.29 & 0.35 & 0.42 & 0.26 \\
\hline S1 D1 & 0.09 & 0.14 & 0.25 & 0.29 & 0.31 & 0.22 \\
\hline S1 D2 & 0.09 & 0.14 & 0.25 & 0.29 & 0.32 & 0.22 \\
\hline S2 D1 & 0.09 & 0.15 & 0.27 & 0.32 & 0.40 & 0.25 \\
\hline \multirow[t]{2}{*}{ S2D2 } & 0.09 & 0.16 & 0.29 & 0.34 & 0.41 & 0.26 \\
\hline & 0.09 & 0.15 & 0.27 & 0.32 & 0.37 & \\
\hline \multicolumn{7}{|c|}{$\begin{array}{c}\text { LSDTRT }=0.005 \text { LSD TRT } . V=0.003 \\
\text { LSD V }=0.002\end{array}$} \\
\hline
\end{tabular}

The speed factor has a significant effect in determining the actual productivity of the operation at all levels of this study. The highest productivity rate was shown at 4.7 $\mathrm{km} . \mathrm{hr}^{\mathbf{1}}$ and it was $0.37 \mathrm{ha} . \mathrm{hr}^{\mathbf{1}}$ The reason for this results is due to the fact that the actual productivity is directly proportional to field speed so that the increased in the field speed has led to increase in the actual productivity and vice versa . the interaction between the two factor had a significanteffect in the actual productivity and that was clear when the combined implement used with shanks points oriented opposite to the plowing direction at the shallow depth (S2D2) with highest speed which has achieved an actual productivity equal to 0.409 ha.hr ${ }^{-1}$ (table 5 ).

\section{Fuel consumption}

Recently; fuelconsumption has dominated the interest of the researchers due to the steady rise in fuel prices it is not easy term to rate because the tractor fuel consumption based on $\mathrm{kg}$ of pull as compared with other vehicles which were rated in $\mathrm{km} . \mathrm{hr}^{-1}$ traveled . Eliminating one operation of the seedbed preparation by combining one light tillage tool can usually save amount of fuel suppose to be consumed by the eliminated operation . the noticed trend of signifies of some related researches showed that the fuel consumption varies with plowing speed and depth among other factor however the correct set up equipment's appropriate counter weight diesel quality correct tire pressure tractor maintenance are the other technical factors that effect consumption. Anyway in this study the fuel consumption test was performed to compare between the moldboard plow when used separately and when it was combined with the ripper in respect to all of the treatment tested . it seems very clear from the fig 4 that the process of plowing using the moldboard plow separately require about43 L.ha $\perp$ however, when using the combined implement (moldboard plow + ripper ) with the shanks points oriented opposite to the plowing direction at the shallow depth the amount of fuel consumed was 49.69
L.ha' ${ }^{1}$ which means that the combined implement has saved about 7.67 L.ha' ${ }^{1}$ compared to the processing of plowing and cultivating each one separately.

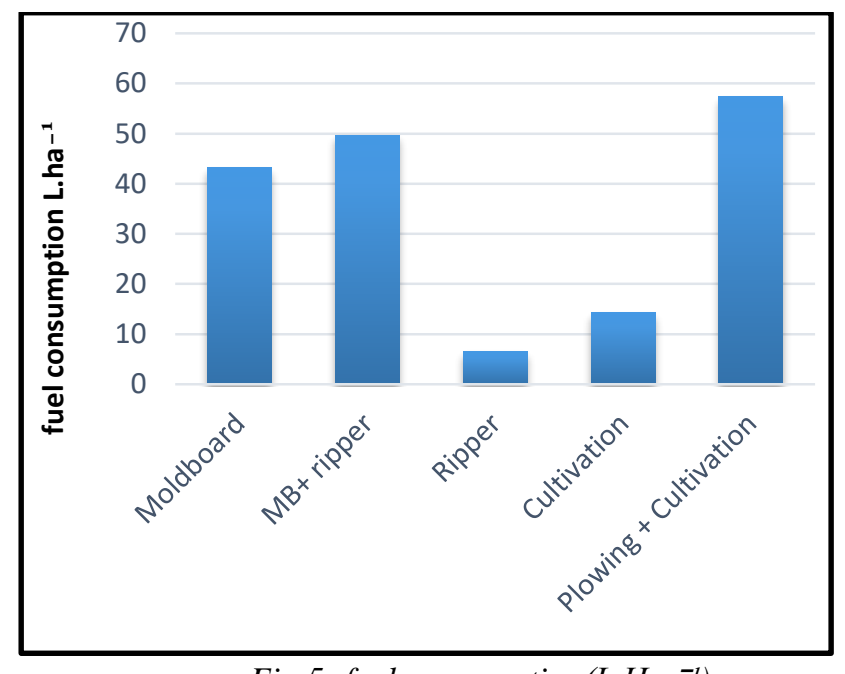

Fig 5: fuel consumption (L.Hec $\left.{ }^{-1}\right)$

\section{CONCLUSION}

In addition to the mentioned advantages the fuel saving is one of the most important features of the combined implement, the direction of the ripper shanks has great influence on the performance of the combinedimplement .Generally the best performance was found when the ripper shanks were oriented opposite to the direction of plowing . The speed of plowing operation had a significant effect on the results in all the parameters studied whether in the use of combined implement or the use of mold board plow alone . In relation to the things that havealready been mentioned the combined implement can a achieve something's as a result such as reduced the number of traffic shortening the time of agricultural process lowering the agricultural production cost as well as reducing fuel consumption .

\section{REFERENCES}

[1] Abo-Habage , M.M.E , kh.A.A. khadi and O.E.M.M. Naeem . 2010 . energy requirement for operating the rotary plow under Egyptian condition .J.Soil sci and Agric Engineering ,Mansoura University's voi . 1(5) : 463-473

[2] Adewoyin , A.O , E.A . Ajav . 2013. Fuel consumption of some factor models for plowing operation in the sandy loam of Nigeria at various speed and plowing depth . Agric Eng int : GIGR Journal vol/15 No.3

[3] Asgill, L.2008 . California Tillage Newsletter . 201 Needham St. Modesto, Calif.

[4] Diman M.2012. SAVING TIME AND FUEL DURING TILLAGE . Proc. of the 2012 Wisconsin Crop Management Conference, Vol. 51 
[5] Ellis , D. 2013 . Efficient 20 Fuel Consumption Database D2.2 Free Farmer's/Forester's User Guide. Version 11/2/2013. Intelligent Energy Eurofor A sustainable Future.

[6] Grisso, R., Z.R. Helsel, and V. Grubinger, 2012. "Reducing Tillage to Save Fuel," eXtension.orgfact sheet.

http://www.extension.org/pages/28317/reducingtillage-to-save-fuel\#.U7Rb4azZeSo.

[7] Harrigan, T.M., Rotz, C.A., 1995. Draft relationships for tillage and seeding equipment. Appl. Eng. Agric. 11 (6), 773-783.

[8] Javadi , A and A.Haji Ahmad . 2006. Effect of a New combined Implement for reducing Secondary Tillage operation 2006 108-6-724-727.

[9] Khattak, M. K.; Ramzan, M.1995. Effect of different tillage implements combination on fuel consumption and yield of maize.: Sarhad Journal of Agriculture 1995 Vol.11 No.2 pp.125-131 ref.13

[10] Leghari N; V. K. OAD , A. A. SHAIKH , A. A. SOOMRO 2016 .Analysis of different tillage implements with respect to reduced fuel consumption, tractor operating speed and its wheel slippage. Sindh Univ. Res. Jour. (Sci. Ser.) Vol. 48 (1) $37-40$ (2016)

[11].Majeet P , R. Swarnkar, V.D. K.Kantilal, P.S. K. Jeetsinh and K. B. Chitharbhai .2016 . Combined Tillage Tools- A Review . Current Agriculture Research Journal vol.4(2) . 179-185.

[12] Moitizi ， G,H Hagentristi ， K.Refenner, H. Weingartnann. 2014 . Effect of working deph and wheel slip on fuel consumption of selected tillage implements , Agriculture Eng int : GI GR Journal voi.16,No.1

[13] Nasr , G.E.Y . Tayel , y.B. Abdelhay, kh.Sabreen .2016.Technical Evaluation of A new combined Implement for seedbed preparation chem Tech vol.a,No.05 pp 193-199

[14] Sahu, R.K., Raheman, H., 2004. Possibility of using passive-passive combination tillage implements for Indian farming system. In:Proceedings of International Conference on Emerging Technologies .

[15] Sahu, R.K., Raheman, H., 2006 .An approach for draft prediction of ombination tillage implements in sandy clay loam soil . Soil \& Tillage Research 90 (2006) 145-155

[16] Servadio ,P. ,S. Bergonzoli and C.Beni . 2016 . Soil tillage systems and wheat yield under climate change scenarios . Agronomy :6(3), 43.

[17] Shafec. A. 1995 . Tillage Machinery . University centre publication, Tehran, Iran .in Agricultural and Food Engineering (Etae-2004), vol. (1),IIT, Kharagpur, 14-17 December, pp. 100-106.
[18] Srivastava , A.C 1940 . Elements of farm machinery . oxford and IBH publishing CO . New Delhi 